IZA DP No. 7193

Unemployment and Subsequent Employment

Stability: Does Labour Market Policy Matter?

Melike Wulfgramm

Lukas Fervers

January 2013 


\title{
Unemployment and Subsequent Employment Stability: Does Labour Market Policy Matter?
}

\author{
Melike Wulfgramm \\ University of Bremen \\ and IZA
}

Lukas Fervers

University of Bremen

\author{
Discussion Paper No. 7193 \\ January 2013
}

\author{
IZA \\ P.O. Box 7240 \\ 53072 Bonn \\ Germany \\ Phone: +49-228-3894-0 \\ Fax: +49-228-3894-180 \\ E-mail: iza@iza.org
}

\begin{abstract}
Any opinions expressed here are those of the author(s) and not those of IZA. Research published in this series may include views on policy, but the institute itself takes no institutional policy positions. The IZA research network is committed to the IZA Guiding Principles of Research Integrity.

The Institute for the Study of Labor (IZA) in Bonn is a local and virtual international research center and a place of communication between science, politics and business. IZA is an independent nonprofit organization supported by Deutsche Post Foundation. The center is associated with the University of Bonn and offers a stimulating research environment through its international network, workshops and conferences, data service, project support, research visits and doctoral program. IZA engages in (i) original and internationally competitive research in all fields of labor economics, (ii) development of policy concepts, and (iii) dissemination of research results and concepts to the interested public.
\end{abstract}

IZA Discussion Papers often represent preliminary work and are circulated to encourage discussion. Citation of such a paper should account for its provisional character. A revised version may be available directly from the author. 


\section{ABSTRACT \\ Unemployment and Subsequent Employment Stability: Does Labour Market Policy Matter?}

This paper analyses the effect of unemployment insurance generosity and active labour market policy on reemployment stability in Europe. Using EU-SILC and OECD data, we conduct discrete time survival analyses with shared frailty specification to identify policy effects at the micro and macro level. Empirical evidence suggests that unemployment benefit receipt is associated with longer reemployment duration at the individual level. Furthermore, countries with more generous unemployment insurance and higher ALMP spending show a more sustainable reintegration record of previously unemployed workers. These results point to a policy trade-off between the well-confirmed disincentive and locking-in effect of unemployment benefits and ALMP programmes on the one hand, and their positive effect on reemployment stability on the other hand.

JEL Classification: J64, J65, J68

Keywords: post-unemployment employment stability, job match quality, reemployment duration, active labour market policy, unemployment benefits

Corresponding author:

Melike Wulfgramm

University of Bremen

Mary-Somerville-Str. 5

28359 Bremen

Germany

E-mail: wulfgramm@uni-bremen.de 


\section{Introduction}

Faced with the challenge of high and persistent unemployment, European policy-makers have been searching for labour market policies that promote quicker reintegration of the unemployed. As a result, two kinds of labour market reforms have been introduced over the last years. On the one hand, income support for the unemployed has become less generous through lower benefit levels, shorter benefit durations and stricter eligibility criteria. These policy measures aim at increasing the exit from unemployment by reducing the well-confirmed disincentive effect of unemployment benefits (Katz and Meyer 1990; van Ours and Vodopievic 2008; Tatsiramos 2009). On the other hand, the focus has been shifted towards activating policy instruments which are designed to increase employment incentives and facilitate quicker matching of supply and demand in the labour market (Eichhorst 2009). In the public and scientific discourse, the costs and benefits of these reforms have mainly been judged with regard to their effect on the exit rate from unemployment.

Despite the importance of shortening unemployment duration, this exclusive focus neglects an essential aspect of the labour market: the sustainability of reintegration, i.e. the post-unemployment employment stability. In this paper, we argue that labour market policy evaluation requires a more comprehensive perspective which considers the long-run effect on reemployment stability, since it is likely to be shaped by passive as well as active labour market policies. In particular, we present empirical evidence for two hypotheses. First, the design of unemployment insurance is expected to matter. If generous unemployment benefits are available, the unemployed do not suffer from severe income losses. While this might lead to longer unemployment duration, it also enables the unemployed to take more time to search for jobs that better match their personal skills thus improving post-unemployment job match quality and employment stability (Ehrenberg and Oaxaca 1976; Burdett 1979). Second, active labour market policy (ALMP) programmes intend to foster reemployment stability. On the one hand, training programmes aim at improving the skill level of the unemployed with a view to enhancing their chances of finding high quality jobs. On the other hand, counselling services tackle information deficits in the labour market, which can be assumed to improve the matching process. Up to now, these effects have been rarely studied at the European level. Using longitudinal EU-SILC and OECD data, we aim to fill this gap by conducting comparative micro and multilevel survival analyses in order to test the hypotheses that generous unemployment benefits and ALMP spending promote reemployment stability.

This paper is organized as follows: In section 2, we elaborate on the theoretically expected effects of labour market policy and put forward our related hypotheses. Moreover, we summarize the results 
of previous microeconometric research in this field. Afterwards, we outline our research design. This includes a detailed discussion of our variables, model specification and estimation technique. In section 4 , we present the results of our econometric analysis. Finally, we present our theoretical conclusions and discuss implications for future policy-making.

\section{Labour Market Policy \& Reemployment Stability}

\subsection{Theoretical Framework}

Both active as well as passive labour market policies can be expected to influence reemployment stability. While it is the main purpose of the unemployment insurance to compensate income losses in case of unemployment, it is also likely to affect (post-unemployment) employment outcomes. The underlying mechanism of this effect lies in the influence unemployment benefits exert on the search behaviour of the unemployed. In the absence of generous unemployment benefits, the unemployed suffer from severe income losses. This creates strong incentives to accept any available job offer, irrespective of its type and quality. To put it the other way around: In presence of generous unemployment benefits, the unemployed will be more selective with regard to available job offers (Katz and Meyer 1990). This affects the labour market in two ways. On the one hand, it can be expected to lead to prolonged unemployment. This is referred to as the disincentive effect of unemployment benefits and has been well confirmed by a huge body of microeconometric literature (e.g. van Ours and Vodopievic 2008; Caliendo et al. 2012; Tatsiramos 2009). On the other hand, it has been argued that this effect on the search behaviour improves post-unemployment job match quality, e.g. reemployment stability. This argument is based on the idea of Burdett (1979) who claimed that unemployment benefits provide a search subsidy: Given sufficient income support in case of unemployment, the unemployed can take more time to search for jobs that match their personal skill profile. Due to substantial information deficits in the labour market, i.e. incomplete information about available job offers, it seems to be convincing to argue that longer search times might be required in order to find the best available job offer. Therefore, it can be expected that generous unemployment benefits improve reemployment stability. Due to the detrimental effects of long-term unemployment, it should be considered that this argument rather applies to short- and medium-term unemployed workers. To sum up, unemployment benefits are expected to increase unemployment duration and reemployment stability simultaneously due to their effect on the search behaviour of the unemployed.

While the effect of passive labour market policy on reemployment stability rather is a side effect, ALMP programmes are directly aimed at fostering employment prospects of the participants. With 
regard to reemployment stability, there are two kinds of programmes which are of particular interest. First, training programmes aim at refreshing skills that have become obsolete due to skillbiased technological innovations and help employees to keep up with the rising skill demands of a knowledge-based economy (Armingeon 2003: 153). By improving the skill level, they are supposed to increase the productivity of the unemployed thus leading to higher demand of employers for these workers. Therefore, training programmes can be expected to improve labour market outcomes. The second relevant programme type are counselling services provided by the Public Employment Services (PES). While the theoretical argument with regard to training programmes is very obvious, the effect of PES is more subtle for two reasons. First of all, PES are a means of tackling information deficits in the labour market. In presence of more comprehensive information about available jobs (job candidates), the quality of the job-matching-process can be assumed to be higher thus improving post-unemployment employment outcomes. Secondly, PES positively affect reemployment stability via an interaction effect with other programmes. When the consultants of the work agencies have more intensive contact with the unemployed, they can design suitable and individualized combinations of different ALMP measures (Card et al. 2010). Therefore, PES also foster reemployment stability as they increase the effectiveness of ALMP programmes as a whole.

All in all, we argue that generous unemployment benefits and ALMP programmes improve reemployment stability.

\subsection{Previous Research}

Up to now, the effect of unemployment insurance generosity on post-unemployment employment outcomes has mainly been limited to micro data analyses from single countries. In short, previous studies have examined whether differences in employment outcomes of reemployed workers can be explained by differences in the income support during their last unemployment spell. In this context, post-unemployment wages, employment stability and type of contract have been taken into account. While all quoted studies have detected a negative effect of unemployment benefit generosity on the exit rate from unemployment, the results concerning post-unemployment employment outcomes are rather mixed. Due to a lack of sufficient micro data in European countries, the analysis has for a long time been restricted to U.S. and Canadian data. Among others, Ehrenberg and Oaxaca (1976) and Belzil (2001) detected a weakly positive effect on wages and employment stability, respectively. More recently, data improvements in European countries encouraged the extension of the country sample. While the positive effect has been confirmed by Gangl (2002), Caliendo et al. (2012), Centeno and Novo (2009), and Lauringson (2012), neither Portugal and Addison (2008), Card et al. (2007) nor van Ours and Vodopievic (2008) can find a significantly positive effect. Using data from 
the European Community Household Panel (ECPH), Tatsiramos (2009) has analysed the effect of unemployment benefits in eight European countries. Once again, it is reported that the overall effect of unemployment benefits is positive. At the same time, the construction of country-specific subsamples shows that this effect cannot be found in all countries. Even though eight countries are included in the sample, the differences between countries are not explicitly tested empirically. In this regard, this paper is the first attempt to explain post-unemployment employment stability by national labour market policy indicators.

Similar to the analysis of unemployment benefit generosity, the effect of ALMP programmes has mainly been tested by microeconometric evaluations. The effect is again measured by postunemployment wages, the type of contract and the probability of being employed in the future. Despite the existence of a huge body of empirical evaluations, it is still difficult to draw a final conclusion. The results differ with respect to the selected countries, programme types and subsamples, while there are often no convincing theoretical arguments that explain these differences. Nevertheless, there are two main conclusions that can be drawn. First of all, training programmes tend to have a negative effect on the employment probability in the short run, but it turns out to be positive in the long run. On the one hand, this approves the existence of a locking-in effect, which causes the negative short-run effect. On the other hand, this evidence confirms that training programmes indeed lead to better post-unemployment employment stability in the long run. Secondly, job search assistance has a positive effect, too, which can already be found after a shorter period of time. Positive long-run effects of ALMP programmes on the employment stability have (among others) been detected for East Germany (Lechner et al. 2007), West Germany (Lechner et al. 2011), France (Crépon et al. 2012) and Denmark (Munch and Skipper 2008). The results concerning post-unemployment wages are very similar. In the long run, a positive effect has been found in Missouri and North Carolina (Dyke et al. 2006), Sweden (Larsson 2003), Norway (Raaum et al. 2002) and Romania (Rodriguez-Planas and Benus 2010). The type of contract is used comparatively rarely as dependent variable. Nevertheless, ALMP measures also tend to have a positive effect on the likelihood to get a regular contract (Caliendo et al. 2008, Cavaco et al. 2004). The validity of this literature review is confirmed by a meta-analysis provided by Card et al. (2010). Broadly speaking, they confirm the finding that job search assistance has a positive effect in the short run, while training programmes only have a positive effect in the long run, which then turns out to be even stronger than the effect of job search assistance. All in all, these findings support the assumption of a positive effect of ALMP programmes on post-unemployment employment stability. 


\section{Research Design \& Data}

We follow a two-stage research design to study the impacts of labour market policy on postunemployment employment stability, using discrete-time multivariate duration models with shared frailty specification. The first stage focusses on the micro-level and thus investigates the connections between individual unemployment benefit receipt and the duration of post-unemployment employment spells. The advantage of this microeconometric approach lies in the high number of observations and the explicit identification of individuals that are directly affected by the policy under study. In the second stage, we analyse whether differences in national labour market policies can explain differences in the post-unemployment employment stability between countries. This results in a nested data structure as the employment stability continues to be measured at the micro level. In order to take this data structure into account, we perform multi-level survival analyses. In particular, we test whether unemployment benefit generosity and the intensity of ALMP are systematically related to post-unemployment employment stability. This multilevel analysis complements microeconometric analyses by overcoming two methodological difficulties. On the one hand, the policy effect indicated by micro variables can result from non-random selection into the relevant policy measure. On the other hand, positive policy effects at the micro level are overestimated when higher employment rates are caused by substitution effects rather than real treatment effects. All in all, this research design allows for a more comprehensive and robust analysis of the assumed policy effects.

\subsection{Data \& Descriptive Statistics}

Our dataset is characterised by a multi-level structure, merging individual data on employment status and socioeconomic characteristics of respondents with information on national labour market policies and macroeconomic conditions at the country level. Table A.1 in the Appendix shows descriptive statistics for both macro as well as micro level variables.

At the micro-level, we use four waves of the European Survey on Income and Living Conditions (EUSILC), covering the years 2005-2008 in a longitudinal survey design. In total, there are observations from Norway, Iceland and all EU-27 countries except for Germany and Malta. To model the length of reemployment spells, i.e. our dependent variable, we rely on retrospective monthly information about the employment status of the respondents. ${ }^{1}$ In order to identify reemployment spells and to control for the duration of previous unemployment length, we construct an unemployment-inflowoutflow sample. Furthermore, we exclude all spells that end in inactivity because we do not have

\footnotetext{
${ }^{1}$ In this context, it should be noted that we refer to employment stability rather than job stability.
} 
sufficient information about the reason for the exit from the labour force. Hence, we restrict our sample to spell sequences that can take two forms:

a) Unemployment inflow - employment - unemployment

b) Unemployment inflow - employment (right-censored).

In total, our final sample includes 20,039 reemployment spells, of which (a) 8,315 end in unemployment and (b) 11,724 are right-censored.

The main independent micro-level variable of interest is a binary indicator on unemployment benefit receipt during the unemployment spell prior to reemployment. Benefit receipt is given on a yearly rather than monthly base and we do not have information about the potential expiry date of benefits. If the information for a spell differs between years, we rely on the data of the last year, as it should affect the exit to employment the most. Cases with more than one unemployment spell per year with benefit receipt require more complex decision rules. We exploit information of adjacent years for overlapping spells where possible while keeping the coding as conservative as possible. Since eight out of the 27 countries do not offer information on benefit receipt in EU-SILC, we have information on prior unemployment benefit receipt for 13,448 reemployment spells. As Table 1 shows, the share of respondents that receive unemployment benefits differs strongly between countries: It ranges between $5.2 \%$ in Bulgaria to $81.2 \%$ in Austria. These cross-national differences may be due to differences in the composition of the unemployed between countries with regard to socioeconomic and employment history variables. At the same time, the magnitude of the differences suggests that labour market policy also plays a major role in the determination of benefit receipt.

Table 1: Unemployment benefit recipients by country

\begin{tabular}{|c|c|c|c|c|c|c|c|}
\hline Country & Prior Ben & eceipt & Total & Country & Prior Ben & eceipt & Total \\
\hline & $\mathrm{N}$ & $\%$ & $\mathrm{~N}$ & & $\mathrm{~N}$ & $\%$ & $\mathrm{~N}$ \\
\hline Austria & 437 & 81.2 & 538 & Lithuania & 46 & 11.6 & 398 \\
\hline Belgium & 238 & 68.2 & 349 & Luxemburg & 220 & 41.1 & 535 \\
\hline Bulgaria & 29 & 5.2 & 555 & Latvia & 105 & 30.7 & 421 \\
\hline Cyprus & 205 & 36.0 & 570 & Poland & 303 & 17.0 & 1781 \\
\hline Czech Republic & 610 & 61.8 & 987 & Portugal & 92 & 22.8 & 403 \\
\hline Estonia & 55 & 14.9 & 370 & Romania & 12 & 14.6 & 82 \\
\hline France & 601 & 61.6 & 975 & Slovenia & 268 & 32.9 & 814 \\
\hline Greece & 143 & 22.2 & 644 & Spain & 770 & 37.5 & 2053 \\
\hline Ireland & 105 & 30.7 & 342 & Sweden & 146 & 51.2 & 285 \\
\hline Italy & 603 & 44.8 & 1346 & Total & 4988 & 37,1 & 13448 \\
\hline
\end{tabular}


Micro-level socioeconomic control variables are age, marital status, educational level, gender and subjective health. Furthermore, we include two variables that are directly representing previous employment histories. Firstly, we control for the duration of the previous unemployment spells. As we limit our sample to post-unemployment-inflow employment spells, we are able to identify the full-length of the unemployment spell without problems of censoring or truncation. Secondly, we include the employment ratio to account for the longer-term labour market history of the respondents. The employment ratio gives the ratio of time in employment as a share of total time since first entry into employment.

Macro-data was extracted from Eurostat as well as the OECD, depending on data availability in the respective data source. The main macro-variables of interest are unemployment benefit generosity as well as intensity of active labour market policy (ALMP). Intensity of ALMP is operationalized by the spending on ALMP per unemployed as a percentage of GDP per capita. In contrast to most other studies, we use the indicator per unemployed rather than simply calculating expenditure as a percentage of GDP. The aggregate spending indicator is strongly influenced by the unemployment rate, i.e. high (low) aggregate spending often results from high (low) unemployment but does not necessarily reflect the amount of money that is available per unemployed. Therefore, our procedure gives a more reliable indicator for the intensity of ALMP. Furthermore, we make use of disaggregated ALMP spending data since ALMP is a highly aggregated category. As our theoretical argument explicitly refers to training measures and PES, we calculate corresponding spending indicators for these two subcategories. To measure unemployment benefit generosity, we rely on benefit replacement rates as well as benefit duration. In line with most other studies that measure benefit generosity, average net replacement rates are calculated as the mean of replacement rates for three income categories and six family types by the OECD. Since the generosity of unemployment benefits also depends on benefit duration, we weight the net replacement rate by a duration indicator which ranges from 0 (no benefits) to 1 (48 months or longer) ${ }^{2}$ :

Unemployment benefit generosity $=$ net replacement rate $*$ duration .

In order to control for the macroeconomic structure of the different countries, we use indicators that cover both long-term economic development as well as short-term business cycle fluctuations that are likely to affect employment stability. GDP per capita (in 1000s of US \$, constant 2000 prices, ppp) gives a rough measure for the overall level of economic development. Unemployment rate change is inserted into the analysis to account for short-term business cycle fluctuations. The effect of

\footnotetext{
${ }^{2}$ Since the duration of benefits can and does vary with the age or employment record of the recipient, the recipient was assumed to be a 40 year old worker with a long and uninterrupted employment record. This is based on the practice by the OECD (e.g. 2007: 17-22).
} 
economic upswings and downturns on the stability of post-unemployment employment is theoretically ambiguous, though. While the probability of dismissals is higher in downturns, so is the probability of being hired, resulting in more selective hiring. Therefore, a positive selection bias is likely to increase the job match quality. Whether this selection effect or the generally adverse business environment dominates the effect on employment stability therefore remains an empirical question. Finally, we include the OECD overall employment protection legislation (EPL) indicator in the analysis to account for policy induced differences in labour market dynamics. Restrictive EPL may lead to longer unemployment and employment spells due to increased costs of hiring and firing.

\subsection{Discrete-time multivariate duration models with shared frailty specification}

Due to the nature of our dependent variable, we estimate duration models that deal with censored data. In specific, we estimate multivariate discrete time models with shared frailty specifications. Although the underlying process of surviving or exiting out of an employment spell is continuous as such, we treat time as discrete as the spell length is observed only in monthly intervals. Our choice of the discrete time model is largely due to the fact that we face a large prevalence of ties and hence a rather high incidence rate in our data set, which militates against the use of continuous models (see Jenkins 2005). In general, the discrete hazard function of the interval-censored employment spells, i.e. the conditional probability of exit into unemployment $(y=1)$ in the interval $t$ given survival until ( $t$ 1), may be written as

$$
h_{i j k l}(t)=\operatorname{Pr}\left(y_{i j k l}(t)=1 \mid y_{i j k l}(t-1)=0\right)
$$

where observations belong to spell $i$ of individual $j$ in country $k$ in year $l$. The discrete time survivor function for $n$ intervals $t$ follows to be

$$
S(t)=\prod_{n=1}^{t}\left(1-h\left(t_{n}\right)\right)
$$

where the monthly intervals refer to analysis time rather than calendar time. To estimate the impact of $b_{i j k l}$, i.e. the benefit indicator for prior unemployment benefit receipt, and the vector of the microlevel control covariates $X_{i j k l}$, one can fit a logistic regression model of the form

$$
\operatorname{logit}\left[h_{i j k l}(t)\right]=\log \left[\frac{h_{i j k l}(t)}{1-h_{i j k l}(t)}\right]=\alpha(t)+\beta_{1} b_{i j k l}+\beta X_{i j k l}
$$


where the vector of micro-level covariates $X_{i j k l}$ is composed of socioeconomic characteristics that are likely to impact the sustainability of labour market reintegration. $\alpha(t)$ is the function of time and represents the baseline hazard in case all covariates take on the value zero. In our case, we model the functional form of the duration dependence by grouping the monthly intervals into 6 larger intervals $D_{1-} D_{6}$, and thus choose a piecewise constant baseline hazard. This model hence treats the baseline hazard to be rather constant within but differ between the following intervals: 1-3, 4-6, 7-9, 10-12, 13-24 and >24 months. We chose this specification of the duration dependence after inspecting the coefficients of the 48 monthly intervals. The functional form of the duration dependence may be written as

$\alpha(t)=\alpha_{1} D_{1}+\ldots+\alpha_{6} D_{6}=\sum_{d=1}^{6} \alpha_{d} * D_{i j k l d}$

As our dataset contains information about the employment records for up to 48 months per respondent, it contains multiple reemployment spells for many individuals. Being thus a typical case of a hierarchical data structure, we expect and indeed find unobserved individual-specific factors that are constant across episodes and may thus affect the hazard of exiting into unemployment in all employment spells of one person. For reasons that cannot be identified in our dataset, some individuals are more prone to failure than others and thus frailty to exit into unemployment is not independent for different spells of the same person. Furthermore, unobserved heterogeneity has implications for the duration dependence which often faces a severe negativity bias due to a selection process that excludes high-frailty individuals in an early stage of the data sample. To control for unobserved heterogeneity, we estimate frailty models that assume shared frailty for spells of the same respondent in the first stage of our empirical analysis. Thus, we include an individual-specific random error term $u_{j k}$ into the micro models to account for unobserved heterogeneity and extend equation (3) into

$\operatorname{logit}\left[h_{i j k l}(t)\right]=\alpha(t)+\beta_{1} b_{i j k l}+\beta_{2} X_{i j k l}+u_{j k}$

This allows a less biased estimation of covariates as well as standard errors than models that treat all observations as independent. Finally, we include country-specific effects in order to test whether our micro-level analysis is robust to the inclusion of these country dummies. Moreover, they allow us to identify country-clusters that offer more sustainable post-unemployment labour market reintegration that cannot be explained by the composition of individuals under observation.

In the second stage, we investigate whether differences in the generosity and design of labour market policy between countries are related to the overall stability of reemployment. In addition to 
the micro-level covariates, the estimation entails the inclusion of the vector of macro-level policy as well as economic variables $Z_{k l}$ that is shared among all spells within a country in a given year. In these models, we refrain from inserting country-fixed effects. The restriction to within variance at the country level would lead to highly inefficient estimation since the variation of our independent variables over time is limited and our time span is rather short. Instead of using country fixed-effects, we control for unobserved heterogeneity between individuals of different countries by modelling the shared frailty specification at the country level. This model thus accounts for a hierarchical data structure in which the employment spells are nested within countries, so that the error terms of spells within countries are not treated as being independent. Hence, the estimated logit regression turns into

$\operatorname{logit}\left[h_{i j k l}(t)\right]=\alpha(t)+\beta X_{i j k l}+\lambda Z_{k l}+u_{k}$

where $u_{k}$ is the random effect at the country level that represents the shared frailty specification.

For the sake of robustness, we double-check our results in a continuous-time framework by estimating a log-logistic model with gamma-distributed shared frailty specification (see Appendix Table A.2). We use a log-logistic distribution as the assumption of strictly increasing or declining hazard rates might fail. In fact, the non-linearity of the time dependence is confirmed in the discretetime models. This approves the validity of our argument that parametric models which assume a strictly increasing/declining hazard are not appropriate in this context. As a further robustness check, we restrict our sample to the first spell of every individual, in order to avoid overrepresentation of individuals with rather discontinuous employment histories (see Appendix A.2). Finally, we construct age and gender-specific subsamples for men and women, young workers, prime age workers and older workers (see Appendix, Table 3.A)

\section{Results and Discussion}

The empirical analysis shows that labour market policy exerts a non-negligible influence on the employment stability of the formerly unemployed. Both differences in employment duration between individuals within countries as well as differences in the aggregated reintegration performance between countries are connected to the policy indicators at the respective level. While section 4.1 focusses on the impact of individual unemployment benefit receipt on differences between individuals, section 4.2 presents the effects of national labour market policy indicators on cross-country variation in post-unemployment employment stability. All tables present the results as odds ratios, i.e. values smaller (bigger) than 1 imply a longer (shorter) employment duration. Further 
robustness checks are shown in Table A.2 in the Appendix. These robustness checks indicate that the results are not sensitive to the estimation technique or the construction of sub-samples.

\subsection{Unemployment benefit receipt and individual reemployment stability}

Model 1 in Table 2 presents the results of the microeconometric analysis that concentrates on the effect of unemployment benefit receipt as well as socioeconomic characteristics on the employment hazard (exit into unemployment). The empirical results show that benefit receipt turns out to have a strong and negative effect on the employment hazard in both models, which is significant at the 0.1 $\%$ level. This effect proofs to be robust to the change of the estimation technique and the controlling for country-specific effects (see Model 2 as well as Table A.2 in the Appendix). The substantial strength of the effect is indicated by the odds ratios of the benefit receipt variable, which is 0.64 in Model 1 and 0.65 in Model 2. Graph 1 shows the impact of unemployment benefits by simulating the survivor functions of two representative individuals that merely differ in their benefit receipt.

Graph 1: Prediction Survivor Function Model 1

Survivor function by UE benefit, all other variables at sample median

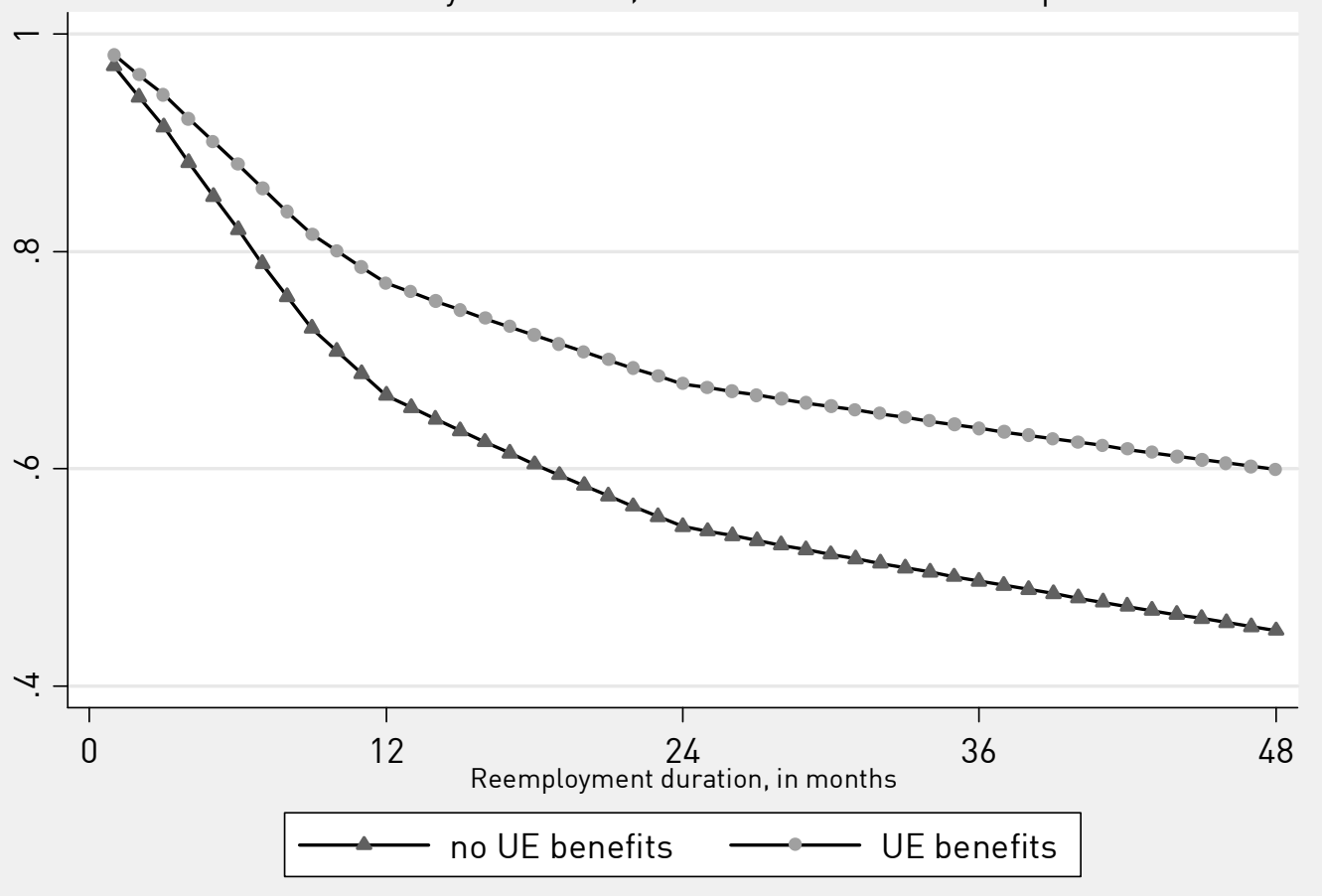

Simulation for the following characteristics: Age $=35$; male; medium education; good health; employment ratio $=0.8$; not married; 4 months of previous unemployment.

Controlling for other characteristics as well as their employment history, individuals who did not receive unemployment benefits have a substantially higher risk of exiting into unemployment again, which endorses the argument that unemployment benefits support the sustainability of labour 
market reintegration. As can be seen in the graphical illustration, the survival rates diverge strongly within the first 12 months after re-entry into employment. After 12 months, $33 \%$ of non-recipients are predicted to have fallen back into unemployment, compared to only $23 \%$ of recipients of unemployment benefits that have the same characteristics. Although failure rates decelerate somewhat, the divergence continues within the second year of reemployment. After 24 months, a substantial difference between the survival rates has been achieved which then remains constant until the end of the observation period. Thus, unemployment benefit receipt mainly affects the hazard rates within the first months of reemployment, but has long-term consequences for the absolute survival rates.

Further socioeconomic control variables tend to confirm the theoretical expectation that individuals with higher human capital endowments have better chances to stay (re)employed. The reintegration proofs to be more stable for individuals who have a higher education, are in a better state of health and have experienced shorter cumulated unemployment duration since their first entry into the labour market. This positive effect of the employment ratio confirms the scarring effect of unemployment that has been found in other studies. While the reemployment appears to be less stable for older workers, gender and marital status do not have a clear linear effect. Furthermore, we find a positive effect of previous unemployment duration on subsequent employment stability. This finding is particularly important from a methodological point of view. Previous research (e.g. Belzil 2001) has found that unemployment duration and reemployment stability are negatively correlated due to unobserved factors which simultaneously reduce unemployment and increase employment stability. The positive correlation between unemployment stability and employment duration indicates that these unobserved factors do not play a major role in our sample.

The difference to previous research can be explained by the strong underrepresentation of long-term unemployed people that can be assumed to be endowed with these unobserved characteristics. Concerns about the endogeneity of our benefit indicator, i.e. a potential correlation with these unobserved factors that might lead to biased estimations, are thus weakened by the positive effect of the previous unemployment duration on employment stability. All in all, these empirical findings support the argument that the search-subsidy character of unemployment benefits may improve the post-unemployment employment outcomes. 


\section{(1)}

Micro-Variables:

UE benefits

UE length

Empl. ratio

Female

Education:

medium

high

Health:

medium

bad

age

Married

$\begin{array}{lll}0.64^{* * *} & (11.2) & 0.65^{* * *} \\ 0.99^{* *} & (3.0) & 0.99^{* *} \\ 0.38^{* * *} & (13.7) & 0.36^{* * *} \\ 1.07 & (1.9) & 1.05\end{array}$

$0.66^{* * *} \quad(8.0)$

$0.79^{* * *}$

$0.50^{* * *}$

(10.2) $\quad 0.53^{* * *}$

$1.19^{* * *}$

$1.44^{* * *}$

$1.01^{* * *}$

0.93
(10.0)

(2.7) $\quad 0.98^{* * *}$

(14.4) $\quad 0.36^{* * *}$

(6.7)

(17.4)

(2.7)

(1.3) $1.09^{* *}$

(4.3) $\quad 0.82^{* * *}$

(9.1) $\quad 0.53^{* * *}$

(10.7)

(4.9) $\quad 1.24^{* * *}$

(5.4) $\quad 1.48^{* * *}$

(1.9)

(4)

\begin{tabular}{|c|c|c|c|c|c|c|c|}
\hline \multicolumn{8}{|c|}{ Country (Reference $=$ Portugal): } \\
\hline $\mathrm{AU}$ & & 0.78 & (1.7) & 1.00 & $(0.0)$ & 0.85 & $(1.4)$ \\
\hline $\mathrm{BE}$ & & 0.89 & $(0.7)$ & 1.03 & $(0.2)$ & $0.74^{*}$ & $(2.2)$ \\
\hline BG & & $0.54^{* * *}$ & $(4.4)$ & $0.55^{* * *}$ & $(4.5)$ & $0.63^{* * *}$ & $(3.7)$ \\
\hline $\mathrm{CY}$ & & 0.88 & $(0.9)$ & 1.07 & $(0.6)$ & 0.87 & $(1.2)$ \\
\hline $\mathrm{CZ}$ & & $0.37^{* * *}$ & $(7.2)$ & $0.40^{* * *}$ & (7.4) & $0.34^{* * *}$ & $(9.1)$ \\
\hline DK & & & & $0.40^{* * *}$ & (3.7) & $0.34^{* * *}$ & $(4.5)$ \\
\hline EE & & $0.59^{* * *}$ & (3.4) & $0.56^{* * *}$ & $(3.7)$ & $0.61^{* * *}$ & (3.4) \\
\hline FI & & & & $1.35^{*}$ & $(2.2)$ & $1.46^{* *}$ & $(3.1)$ \\
\hline FR & & 0.88 & $(1.1)$ & 0.93 & $(0.7)$ & $0.77^{*}$ & $(2.4)$ \\
\hline GR & & $1.28^{*}$ & (2.0) & $1.56^{* * *}$ & (3.7) & 1.21 & $(1.7)$ \\
\hline $\mathrm{HU}$ & & & & $1.29^{*}$ & $(2.1)$ & 0.83 & $(1.7)$ \\
\hline IS & & & & 0.71 & $(1.1)$ & $0.58^{*}$ & $(2.3)$ \\
\hline IE & & 0.92 & $(0.5)$ & 1.09 & $(0.6)$ & 1.03 & $(0.2)$ \\
\hline IT & & 0.90 & $(0.9)$ & $1.24^{*}$ & $(2.0)$ & 1.15 & $(1.4)$ \\
\hline LV & & $0.65^{* *}$ & (2.9) & $0.69^{* *}$ & (2.7) & $0.70^{* *}$ & (2.7) \\
\hline LT & & 0.76 & (1.9) & 0.79 & (1.7) & 0.78 & (1.9) \\
\hline LU & & $0.76^{*}$ & (2.0) & 0.79 & (1.9) & $0.67^{* *}$ & (3.2) \\
\hline NL & & & & 1.11 & $(0.7)$ & 1.00 & $(0.0)$ \\
\hline $\mathrm{NO}$ & & & & 0.99 & $(0.0)$ & 0.71 & $(2.0)$ \\
\hline PL & & 0.84 & $(1.6)$ & 0.83 & (1.7) & $0.79^{*}$ & $(2.3)$ \\
\hline RO & & $0.53^{*}$ & (2.4) & $0.47^{* *}$ & (2.8) & $0.55^{*}$ & (2.3) \\
\hline SK & & & & $0.36^{* * *}$ & (6.9) & $0.31^{* * *}$ & (8.7) \\
\hline SI & & $0.52^{* * *}$ & (3.7) & $0.53^{* * *}$ & (3.8) & $0.55^{* * *}$ & (5.0) \\
\hline ES & & 1.17 & (1.4) & $1.32^{* *}$ & (2.6) & 1.17 & (1.6) \\
\hline SE & & $1.71^{* * *}$ & (3.4) & $1.48^{* *}$ & (2.8) & $1.39^{*}$ & (2.5) \\
\hline UK & & & & $1.50^{*}$ & (2.3) & 0.81 & (1.7) \\
\hline $\mathrm{N}$ & 131325 & 131325 & & 177859 & & 201923 & \\
\hline $\mathrm{N}$ countries & 19 & 19 & & 27 & & 27 & \\
\hline
\end{tabular}

Odds ratios; Absolute $z$ statistics in parentheses; discrete time logit model, duration dependence modelled as piecewise constant, shared frailty at the individual level; ${ }^{*} p<0.05,{ }^{* *} p<0.01,{ }^{* * *} p<0.001$ 


\subsection{National labour market policy and cross-country differences in reemployment stability}

Next to serving as a robustness test for the micro-effects, including country dummies also constitutes the first step towards the analysis of national differences in employment stability. Model 4 can be interpreted as a basic descriptive cross-country comparison, which ignores differences in the socioeconomic composition of the reemployed workers. The inclusion of micro-level variables in Model 3 controls for compositional effects and can thus be interpreted as real country specific effects that have to be explained by macro variables. A comparison of both models shows that the results are rather similar, but differ for some countries. For example, the coefficient of UK changes from 0.8 (z-value 1.7) in Model 4 to 1.5 (2.3) in Model 3, implying compositional effects. With and without the inclusion of micro variables, significant country specific effects can be observed. Surprisingly, countries which are usually found to belong to one cluster in comparative research, e.g. the Scandinavian, Continental-European or Anglo-Saxon cluster (Esping-Andersen 1990), show very inconsistent results. For instance, Denmark turns out to reach the most sustainable reintegration of all countries, while Sweden is one of the countries with the least stable reintegration. While the familiar country clusters cannot be observed, the analysis reveals that reemployment appears to be much more sustainable in Central and Eastern European (CEE) countries. Bulgaria, the Czech Republic, Estonia, Romania, Slovakia and Slovenia have odds ratios lower than 0.6 in both models, which is not reached by any Western European country except for Denmark. Systematic differences in the macroeconomic and macropolitical structure of Western and CEE countries remain to influence the results even after the inclusion of economic indicators. Therefore, we include a dummy variable for CEE countries in the macro-micro estimations or restrict the analysis to Western European countries.

The macro-micro models in Table 3 combine the micro variables (except for benefit receipt), macro level LMP indicators and all macroeconomic control variables. Generally speaking, the macro variables tend to be less significant than the micro variables, which is mainly due to the far lower number of observations ( 21 countries for up to 4 years compared to more than 12,000 individual spells). With regard to the LMP variables, the direction of the coefficients is consistent with our theoretical expectations. Model 5 shows that the reemployment duration of previously unemployed is significantly longer in countries with higher levels of aggregated ALMP spending. The odds ratio is 0.16 and the coefficient is significant at the $0.1 \%$ level. Given the somewhat complex interpretation of odds ratios in case of variables that are not dichotomous, Graph 2 shows a simulation that predicts the survival functions of two hypothetical persons with all individual characteristics at the sample median. 
Table 3: Determinants of reemployment stability, macro and micro level

(5) (6) (7)

(9)

\begin{tabular}{|c|c|c|c|c|c|c|c|c|c|c|}
\hline \multicolumn{11}{|c|}{ Micro-Variables: } \\
\hline UE length & $0.98^{* * *}$ & (7.6) & $0.98^{* * *}$ & (7.7) & $0.98^{* * *}$ & (7.1) & $0.98^{* * *}$ & (7.7) & $0.98^{* * *}$ & (7.6) \\
\hline Empl. ratio & $0.44^{* * *}$ & (16.1) & $0.44^{* * *}$ & (16.2) & $0.45^{* * *}$ & (13.1) & $0.44^{* * *}$ & (16.2) & $0.44^{* * *}$ & (16.1) \\
\hline Female & $1.11^{* * *}$ & (3.7) & $1.11^{* * *}$ & (3.7) & $1.17^{* * *}$ & $(5.2)$ & $1.10^{* * *}$ & (3.7) & $1.11^{* * *}$ & (3.7) \\
\hline $\begin{array}{l}\text { Education: } \\
\text { medium }\end{array}$ & $0.86^{* * *}$ & (3.7) & $0.86^{* * *}$ & (3.7) & $0.87^{* *}$ & (3.1) & $0.86^{* * *}$ & (3.7) & $0.86^{* * *}$ & (3.7) \\
\hline high & $0.61^{* * *}$ & $(9.5)$ & $0.61^{* * *}$ & (9.6) & $0.62^{* * *}$ & $(8.4)$ & $0.61^{* * *}$ & $(9.5)$ & $0.61^{* * *}$ & (9.6) \\
\hline $\begin{array}{l}\text { Health: } \\
\text { medium }\end{array}$ & $1.17^{* * *}$ & (4.4) & $1.17^{* * *}$ & (4.4) & $1.13^{* *}$ & (2.9) & $1.17^{* * *}$ & (4.4) & $1.17^{* * *}$ & (4.4) \\
\hline bad & $1.34^{* * *}$ & $(4.7)$ & $1.34^{* * *}$ & $(4.7)$ & $1.26^{* *}$ & $(2.9)$ & $1.34^{* * *}$ & $(4.7)$ & $1.34^{* * *}$ & $(4.7)$ \\
\hline Age & $1.01^{* * *}$ & $(8.3)$ & $1.01^{* * *}$ & $(8.2)$ & $1.01^{* * *}$ & $(6.5)$ & $1.01^{* * *}$ & $(8.3)$ & $1.01^{* * *}$ & $(8.2)$ \\
\hline Married & 0.97 & $(1.1)$ & 0.97 & $(1.0)$ & 0.98 & $(0.6)$ & 0.97 & $(1.1)$ & 0.97 & (1.1) \\
\hline \multicolumn{11}{|c|}{ Macro-Variables: } \\
\hline ALMP & $0.16^{* * *}$ & $(4.0)$ & T & (1.4) & & (J.1) & & & & \\
\hline Training & & & & & & & & & $0.018^{* *}$ & (3.3) \\
\hline PES & & & & & & & $0.0090^{* *}$ & $(2.9)$ & & \\
\hline EPL & 1.04 & $(0.3)$ & 1.14 & $(1.2)$ & 1.05 & $(0.8)$ & 1.00 & $(0.0)$ & 1.14 & $(1.0)$ \\
\hline UE rate change & $0.95^{* * *}$ & (3.6) & $0.96^{*}$ & $(2.5)$ & $0.96^{*}$ & $(2.3)$ & $0.96^{* *}$ & $(2.7)$ & $0.96^{* *}$ & (2.9) \\
\hline GDP/capita & $0.98^{* *}$ & (2.9) & $0.97^{* * *}$ & (3.9) & $0.98^{* * *}$ & $(4.1)$ & $0.97^{* * *}$ & (3.3) & $0.97^{* * *}$ & (3.5) \\
\hline CEE & $0.29^{* * *}$ & $(5.9)$ & $0.32^{* * *}$ & $(5.5)$ & & & $0.34^{* * *}$ & (5.3) & $0.30^{* * *}$ & (5.5) \\
\hline$N$ & 143930 & & 143930 & & 95511 & & 143930 & & 143930 & \\
\hline$N$ countries & 21 & & 21 & & 15 & & 21 & & 21 & \\
\hline
\end{tabular}

Odds ratios; Absolute $z$ statistics in parentheses; Discrete time logit model, duration dependence modelled as piecewise constant, shared frailty at the country level; ${ }^{*} p<0.05,{ }^{* *} p<0.01,{ }^{* * *} p<0.001$

While it is assumed that all macro control variables are identical for both individuals, one individual is assumed to live in a country with high ALMP spending (one standard deviation above the mean) while the other lives in a country with low ALMP spending (one standard deviation below the mean). Model 5 predicts that the chances to have re-entered unemployment within the first 12 months after reemployment are $64 \%$ in the low-ALMP country compared to only $45 \%$ in the high-ALMP country. As our theoretical argument explicitly refers to the effect of PES and training programmes, we have estimated the effect of the corresponding subindicators in Models 8 and 9. Both disaggregated ALMP indicators have a significant negative impact on the employment hazard at the $1 \%$ level, meaning more stable reemployment. Counselling services and training programmes provided and/or financed by employment agencies proof to be an effective means of improving post-unemployment employment stability. This supports the argument that ALMP programmes raise the skill level of the workforce and tackle information deficits. 
Survivor function by ALMP spending, all other variables at sample median

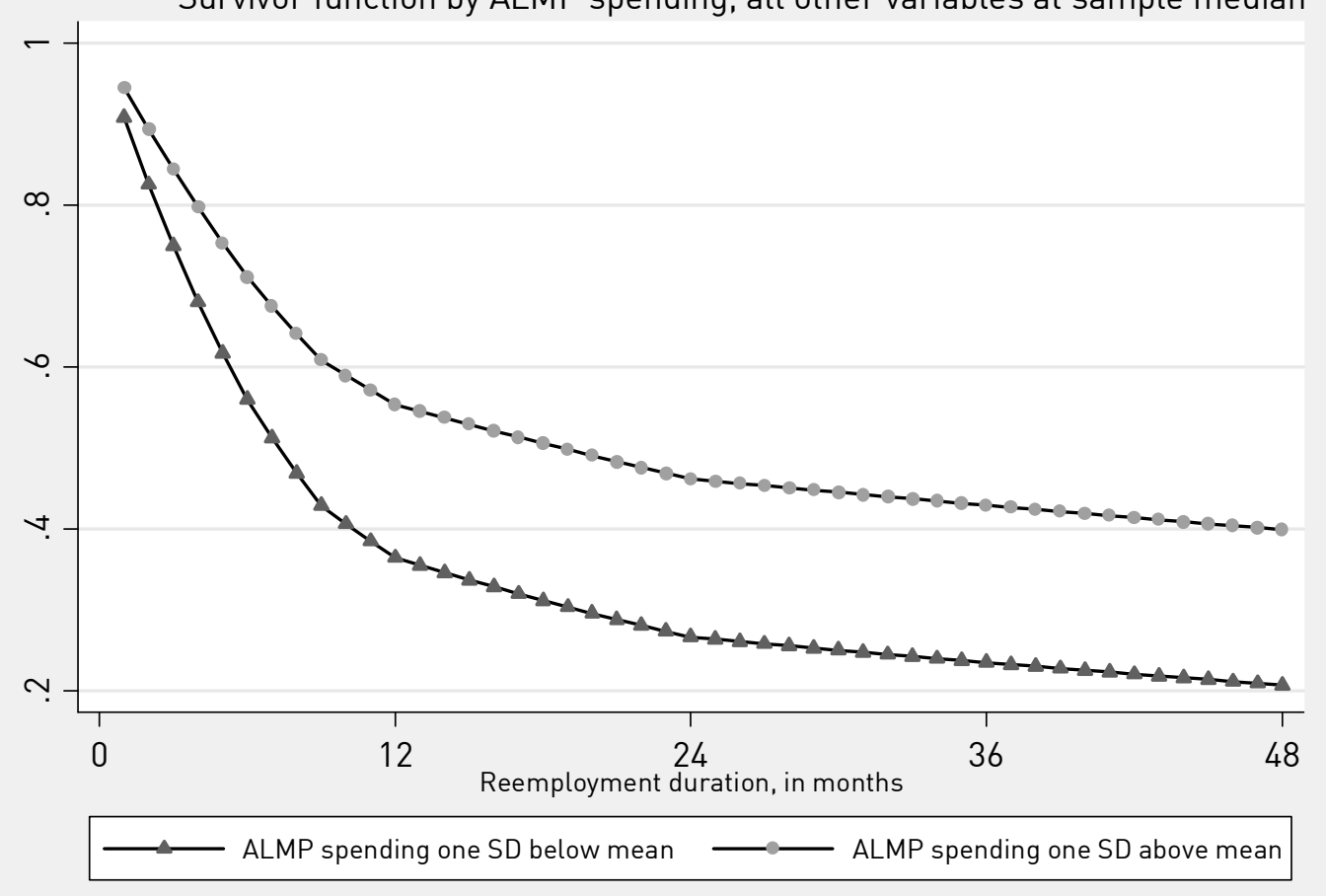

Simulation for the following characteristics: Age $=34$; male; medium education; good health; employment ratio $=0.8$; not married; 4 months of previous unemployment; gdp per capita $=24.7$ thousand US $\$$; unemployment rate change $=-0.6 ; \mathrm{EPL}=1.96 ; \mathrm{CEE}=0$.

The effect of unemployment benefit generosity is estimated in Models 6 and 7. The odds ratio in Model 6 is 0.57 , indicating a negative effect on the employment hazard, while the reported z-value (1.4) shows that the effect is rather insignificant. As the CEE countries have proven to be structurally different from Western Europe, Model 7 replicates the analysis for Western European labour markets only ${ }^{3}$. The direction of the effect is in line with Model 6, showing more stable reemployment in countries with more generous unemployment benefits. In Western Europe, this effect is significant at the $1 \%$ level. The influence of the PLMP variable thus proves somewhat less robust than the theoretical expectations predict. However, while conventional levels of significance are not met in all models, the direction of the effect is homogenous across model specifications and in line with our hypothesis. Summarizing the results from the micro as well as the macro-micro analysis, the evidence strongly suggests a positive connection between unemployment benefits and subsequent reemployment duration. The empirical analysis in this paper supports the argument that generous unemployment benefits may act as a search subsidy that improves the job match quality of the reemployed.

\footnotetext{
${ }^{3}$ The same subsample has also been analysed with respect to ALMP. As shown in the appendix, the effect of ALMP spending is not sensitive to the country sample.
} 
Among the macro-level control variables, especially GDP per capita and the CEE variable proof to be connected to reemployment duration. As expected, the CEE dummy is below 1 and is highly significant at the $0.1 \%$ level in all models. This confirms our argument that there are genuine differences between Central Eastern and Western European countries which cannot be captured by our macro variables. A higher GDP per capita is positively related to the reintegration performance of countries as well. In contrast, the effect of unemployment rate changes appears to be countercyclical, suggesting that those people that are actually hired in economic downturns exhibit better job match quality. Finally, the EPL indicator proves to be insignificant in all models, dismissing the institutional restrictions as a substantial determinant of reemployment stability in our analysis.

\section{Summary/Conclusion}

Empirical observations reveal that European labour markets have undergone remarkable structural changes during the last years. Decreasing tenure rates and growing job insecurity have given rise to a higher incidence of interrupted employment histories which are characterized by alternating periods of employment, inactivity and unemployment. Under these circumstances, the importance of stable labour market reintegration is constantly increasing. This paper shows that reemployment stability is to a large degree influenced by labour market policy in two ways. On the one hand, generous income support for the unemployed promotes reemployment stability. Recipients of unemployment benefits achieve substantially more stable reemployment than their counterparts who do not receive unemployment benefits. At the same time, countries which are characterized by more generous unemployment insurance tend to reach more stable reemployment. This confirms the argument that unemployment benefits act as a search subsidy thus improving job-match quality. On the other hand, reemployment stability appears to be higher when countries spend more on training programmes and counselling services provided by the PES. Once again, these results provide an empirical confirmation for our argument that ALMP programmes foster reemployment stability via skill level increases and information deficit reductions. Methodologically, the analysis has been based on the comparison of individuals as well as a comparison of labour market policy indicators at the macro level. In this regard, this paper makes an innovative contribution to the scientific discussion as it analyses the effect of labour market policy on reemployment stability at the micro and the macro level for the first time.

At the same time, this paper reaches beyond the purely academic debate due to its substantial policy implications. As mentioned in the introduction, recent activating labour market reforms in Europe have focussed on shortening unemployment duration. Given the high and persistent unemployment in many European countries, there is no doubt that this has to be a major concern of policy-makers. 
Nevertheless, this exclusive focus turns out to be short-sighted as it ignores the long-run effect of labour market policy on the stability of labour market reintegration. When the gains of shorter unemployment duration induced by benefit reductions and workfare policies are paid for by unstable reemployment and higher risk of future unemployment, labour market reforms can result in an exhausting zero-sum game. Finding the right balance between policies that shorten unemployment duration and those that increase reemployment stability as well as searching for policies that simultaneously fulfil both aims will remain major challenges for European policy makers during the next years and decades. In this context, future labour market research should support policy makers in finding efficient and innovative policy tools by addressing open research questions such as the interplay of active and passive labour market policies. 


\section{Appendix: Descriptive Statistics \& Robustness Checks}

Table A.1: Descriptive statistics

\begin{tabular}{|c|c|c|c|c|c|}
\hline & & Total & & $\begin{array}{l}\text { No prior } \\
\text { benefits }\end{array}$ & $\begin{array}{r}\text { Prior } \\
\text { benefits }\end{array}$ \\
\hline Variable & $\mathrm{N}$ & Mean & $\begin{array}{c}\text { Standard } \\
\text { Deviation }\end{array}$ & Mean & Mean \\
\hline \multicolumn{6}{|l|}{ Micro-Variables: } \\
\hline Prior unemployment benefit receipt & 13,448 & 0.37 & & & \\
\hline Female & 20,055 & 0.49 & & 0.46 & 0.52 \\
\hline Married & 20,049 & 0.43 & & 0.39 & 0.52 \\
\hline Health: Good & 19,168 & 0.77 & & 0.77 & 0.79 \\
\hline Fair & 19,168 & 0.19 & & 0.19 & 0.18 \\
\hline $\mathrm{Bad}$ & 19,168 & 0.04 & & 0.05 & 0.04 \\
\hline Education: Low & 19,896 & 0.11 & & 0.13 & 0.11 \\
\hline Medium & 19,896 & 0.71 & & 0.68 & 0.71 \\
\hline High & 19,896 & 0.18 & & 0.19 & 0.18 \\
\hline Age & 20,055 & 35.43 & 11.54 & 33.35 & 36.91 \\
\hline Employment ratio & 17,780 & 0.72 & 0.26 & 0.67 & 0.78 \\
\hline Unemployment length & 20,055 & 5.18 & 4.83 & 5.57 & 5.42 \\
\hline \multicolumn{6}{|l|}{ Macro-Variables: } \\
\hline PLMP & 98 & 0.24 & 0.17 & & \\
\hline ALMP* & 99 & 0.20 & 0.15 & & \\
\hline Training* & 99 & 0.06 & 0.05 & & \\
\hline PES* & 99 & 0.05 & 0.04 & & \\
\hline GDP per capita** & 102 & 24.97 & 11.47 & & \\
\hline Unemployment rate & 100 & 6.78 & 2.64 & & \\
\hline Unemployment rate change & 100 & -0.57 & 1.1 & & \\
\hline EPL & 75 & 2.08 & 0.69 & & \\
\hline
\end{tabular}


Table A.2 Robustness checks

$\begin{array}{llll}(10) & (11) & (12) & (13) \\ \mathrm{c} & \mathrm{d} & \mathrm{d} & \mathrm{d}\end{array}$

\section{Micro-Variables:}

\begin{tabular}{|c|c|c|c|c|c|c|c|c|}
\hline UE benefits & $1.59^{* * *}$ & $(13.1)$ & $0.69^{* * *}$ & $(8.0)$ & & & & \\
\hline UE length & 1.00 & $(0.4)$ & $0.99^{* *}$ & $(2.8)$ & $0.99^{* * *}$ & $(4.5)$ & $0.98^{* * *}$ & $(7.1)$ \\
\hline Empl. ratio & $2.41^{* * *}$ & $(14.0)$ & $0.44^{* * *}$ & $(10.1)$ & $0.44^{* * *}$ & (14.1) & $0.46^{* * *}$ & (13.1) \\
\hline Female & $0.93^{*}$ & $(2.0)$ & 1.06 & $(1.6)$ & & & & \\
\hline \multicolumn{9}{|l|}{ Education: } \\
\hline medium & $1.35^{* * *}$ & $(6.3)$ & $0.65^{* * *}$ & $(7.5)$ & $0.84^{* * *}$ & $(3.5)$ & $0.87^{* *}$ & $(3.0)$ \\
\hline high & $1.67^{* * *}$ & $(8.4)$ & $0.50^{* * *}$ & $(9.3)$ & $0.60^{* * *}$ & $(8.3)$ & $0.62^{* * *}$ & $(8.3)$ \\
\hline \multicolumn{9}{|l|}{ Health: } \\
\hline medium & $0.85^{* * *}$ & (3.9) & $1.18^{* *}$ & $(3.3)$ & $1.20^{* * *}$ & $(4.4)$ & $1.13^{* *}$ & $(2.9)$ \\
\hline bad & $0.77^{* * *}$ & $(3.4)$ & $1.48^{* * *}$ & $(4.3)$ & $1.41^{* * *}$ & $(4.7)$ & $1.26^{* *}$ & $(2.9)$ \\
\hline Age & $0.99^{* * *}$ & $(3.7)$ & $1.01^{* * *}$ & $(4.7)$ & $1.01^{* * *}$ & $(5.8)$ & $1.01^{* * *}$ & $(6.5)$ \\
\hline Married & 1.04 & $(1.1)$ & 0.93 & $(1.7)$ & 0.96 & $(1.2)$ & 0.98 & $(0.6)$ \\
\hline \multicolumn{9}{|c|}{ Macro-Variables: } \\
\hline ALMP & & & & & $0.12^{* * *}$ & $(4.0)$ & $0.36^{* *}$ & $(3.2)$ \\
\hline EPL & & & & & 0.95 & $(0.4)$ & 0.95 & $(0.8)$ \\
\hline UE rate change & & & & & $0.93^{* * *}$ & $(3.8)$ & $0.95^{* *}$ & $(3.1)$ \\
\hline GDP/capita & & & & & $0.97^{* *}$ & $(2.9)$ & $0.99^{* *}$ & $(2.9)$ \\
\hline CEE & & & & & $0.22^{* * *}$ & $(6.0)$ & & \\
\hline$N$ & 12225 & & 112354 & & 117699 & & 95511 & \\
\hline$N$ countries & 19 & & 19 & & 21 & & 15 & \\
\hline
\end{tabular}

Exponentiated coefficients; Absolute $\mathrm{z}$ statistics in parentheses; $\mathrm{c}=$ continuous, logl, gamma shared frailty, values above 1 indicate longer employment duration; $d=$ discrete time, duration dependence modeled as piecewise constant, shared frailty, values above 1 indicate shorter employment duration; In models 11 and 12, we have excluded multiple spells, in model 13, we have excluded CEE countries, ${ }^{*} p<0.05,{ }^{* *} p<0.01,{ }^{* * *} p<0.001$

Table A.3: Subsamples by sex and age

\begin{tabular}{|c|c|c|c|c|c|c|c|c|c|c|}
\hline \multirow{2}{*}{ UE benefits } & \multicolumn{2}{|l|}{$\begin{array}{l}\text { (14) } \\
\text { men }\end{array}$} & \multicolumn{2}{|l|}{$\begin{array}{l}(15) \\
\text { women }\end{array}$} & \multicolumn{2}{|c|}{$\begin{array}{l}(16) \\
\text { Age }<25\end{array}$} & \multicolumn{2}{|c|}{$\begin{array}{l}(17) \\
\text { Age 25-49 }\end{array}$} & \multicolumn{2}{|c|}{$\begin{array}{l}(18) \\
\text { Age } \geq 50\end{array}$} \\
\hline & $0.57^{* * *}$ & $(9.7)$ & $0.72^{* * *}$ & $(5.9)$ & $0.62^{* * *}$ & $(4.5)$ & $0.61^{* * *}$ & $(10.1)$ & $0.80^{*}$ & $(2.3)$ \\
\hline UE length & 0.99 & (1.3) & $0.99^{* *}$ & $(2.8)$ & 0.99 & $(1.1)$ & $0.98^{* *}$ & $(3.2)$ & 1.00 & $(0.0)$ \\
\hline Empl. ratio & $0.36^{* * *}$ & $(10.1)$ & $0.41^{* * *}$ & $(9.2)$ & $0.41^{* * *}$ & $(7.4)$ & $0.37^{* * *}$ & $(10.5)$ & $0.28^{* * *}$ & (5.3) \\
\hline Female & & & & & $1.19^{*}$ & $(2.1)$ & 1.07 & $(1.5)$ & 0.88 & (1.3) \\
\hline $\begin{array}{l}\text { Education: } \\
\text { medium }\end{array}$ & $0.68^{* * *}$ & $(5.7)$ & $0.61^{* * *}$ & $(6.0)$ & $0.56^{* * *}$ & $(4.0)$ & $0.70^{* * *}$ & $(5.2)$ & $0.60^{* * *}$ & $(5.1)$ \\
\hline high & $0.46^{* * *}$ & $(7.7)$ & $0.49^{* * *}$ & $(7.2)$ & $0.36^{* * *}$ & $(5.4)$ & $0.55^{* * *}$ & $(7.0)$ & $0.46^{* * *}$ & (4.0) \\
\hline $\begin{array}{l}\text { Health: } \\
\text { medium }\end{array}$ & $1.28^{* * *}$ & $(3.8)$ & 1.09 & $(1.2)$ & 1.20 & $(1.3)$ & $1.16^{*}$ & $(2.5)$ & $1.30^{* *}$ & $(2.6)$ \\
\hline bad & $1.53^{* * *}$ & $(3.7)$ & $1.32^{*}$ & $(2.2)$ & $2.24^{* *}$ & $(2.7)$ & $1.43^{* *}$ & $(3.2)$ & $1.39^{*}$ & $(2.2)$ \\
\hline Age & $1.02^{* * *}$ & $(6.2)$ & 1.00 & $(1.1)$ & 1.00 & $(0.2)$ & $1.01^{* * *}$ & $(3.5)$ & $1.03^{*}$ & $(2.2)$ \\
\hline Married & $0.81^{* * *}$ & $(3.5)$ & 1.07 & $(1.1)$ & 1.20 & $(1.2)$ & 0.92 & (1.7) & 0.86 & (1.5) \\
\hline$N$ & 68499 & & 62826 & & 28732 & & 85827 & & 16766 & \\
\hline
\end{tabular}




\section{References}

Andrén T, Gustafsson B. Income Effects from Labour Market Training Programmes in Sweden during the 1980s and 1990s. International Journal of Manpower 2004; 25(8); 688-713.

Armingeon K 2003. Die Politische Ökonomie der Arbeitslosigkeit. In: Obinger H, Wagschal, U and Kittel B (Eds), Politische Ökonomie: Demokratie und wirtschaftliche Leistungsfähigkeit. VS Verlag: Wiesbaden; 2003. p. 149-173.

Belzil C. Unemployment Insurance and Subsequent Job Duration: Job Matching versus Unobserved Heterogeneity, Journal of Applied Econometrics 2001; 16(5), 619-636.

Burdett K. Unemployment Insurance Payments as a Search Subsidy: a Theoretical Analysis. Economic Inquiry 1979; 17 (3), 333-343.

Caliendo M, Hujer R and Thomsen SL 2008. The Employment Effects of Job Creation Schemes in Germany: a Microeconometric Evaluation. In: Millimet D, Smith J and Vytlacil E (Eds), Advances in econometrics vol. 2. Estimating and evaluating treatment effects in econometrics. Elsevier: Amsterdam; 2008. p. 383-430.

Caliendo M, Tatsiramos K and Uhlendorff A. Benefit duration, Unemployment Duration and Job Match Quality: A Regression-Discontinuity Approach. Journal of Applied Econometrics, 2012. Early view, doi: 10.1002/jae.2293.

Card D, Chetty R and Weber A. Cash-On-Hand and Competing Models of Intertemporal Behavior: New Evidence from the Labor Market. The Quarterly Journal of Economics 2007; 122(4); $1511-1560$.

Card D, Kluve J, Weber A. Active Labour Market policy Evaluations. A Meta-Analysis. The Economic Journal 2010;120; 452-477.

Cavaco S, Fougère D and Pouget J. Estimating the Effect of a Retraining Programme for Displaced Workers on their Transition to Permanent Jobs. IZA Discussion Paper No. 1513; 2004.

Centeno M, Novo AA. The Gains of Unemployment Insurance to Job Match Quality in the Portuguese Labour Market. Economic Bulletin and Financial Stability Report Articles 2008; 43-54.

Crépon B, Ferracci M and Foougère D. Training the Unemployed in France: How Does it Affect Unemployment Duration and Recurrence? Annals of Economics and Statistics 2012; 107-108; 175-199.

Dyke A, Heinrich CJ, Mueser PR, Troske KR and Jeon KS. The Effects of Welfare-to-Work Programme Activities on Labor Market Outcomes. Journal of Labor Economics 2006; 24(3); $567-606$.

Ehrenberg RG, Oaxaca RL. Unemployment Insurance, Duration of Unemployment, and Subsequent Wage Gain. The American Economic Review 1976; 66(5); 754-766.

Eichhorst W, Kaufmann O and Konle-Seidel R. Bringing the Jobless into Work? Experiences with Activation Schemes in Europe and the US. Springer Verlag: Berlin; 2009.

Esping-Andersen G. The Three Worlds of Welfare Capitalism. Polity Press: Cambridge; 1990.

Gangl M. Unemployment Benefits as a Search Subsidy: New Evidence on Duration and Wage Effects on Unemployment Insurance. Discussion Paper FS I 02-208; 2002.

Jenkins SP. Survival Analysis. Unpublished Manuscript, Institute for Social and Economic Research, University of Essex; 2004. 
Katz LF, Meyer BD. The Impact of the potential Duration of Unemployment Benefits on the Duration of Unemployment. Journal of Public Economics 1990; 41(1); 45-72.

Larsson L. Evaluation of Swedish Youth Labour Market Programmes. Journal of Human Resources 2003; 38(4); 891-927.

Lauringson A.The Impact of the Generosity of Unemployment Benefits on Estonian Labour Market Outcomes in a Period of Crisis. Dissertationes Rerum Oeconomicarum Universitatis Tartuensis No. 44. Tartu University Press: Tartu; 2012.

Lechner M., Miquel R. and Wunsch C. The Curse and Blessing of Training the Unemployed in a Changing Economy: the Case of East Germany after Unification. German Economic Review 2007; 4(8); 468-507.

Lechner M., Miquel R and Wunsch C. Long-run Effects of Public Sector Sponsored Training in West Germany. Journal of the European Economic Association 2011; 9(4); 742-784.

Munch JR, Skipper L 2008. Programme Participation, Labor Force Dynamics, and Accepted Wage Rates. In: Fomby T, Hill TC, Millimet DL, Smith JA, Vytlacil EJ (Eds), Modelling and Evaluating Treatment Effects in Econometrics (Advances in Econometrics, Volume 21). Emerald Group Publishing Limited 2008. p. 197-262.

OECD. Benefits and Wages. OECD Indicators. OECD Publishing: Paris; 2007.

OECD. Benefits and Wages: Country-specific Information. 2010. online available at: http://www.oecd.org/social/socialpoliciesanddata/benefitsandwagescountryspecificinformation .htm (Accesed on 28 November 2012).

Portugal P, Addison JT. Six Ways to Leave Unemployment. Scottish Journal of Political Economy 2008; 55(4); 393-419.

Raaum O, Torp H and Zhang T. Do Individual Program Effects Exceed the Costs? Norwegian Evidence on Long Run Effects of Labour Market Training. Memorandum 15: Department of Economics, University of Oslo. 2002.

Rodriguez-Planas N, Benus J. Evaluating Active Labour Market Programs in Romania. Empirical Economics 2010; 38(1); 65-84.

Tatsiramos K. Unemployment Insurance in Europe: Unemployment Duration and Subsequent Employment Stability. Journal of the European Economic Association 2009; 7(6); 1225-1260.

Van Ours JC, Vodopivec M. Does Reducing Unemployment Insurance Generosity Reduce Job Match Quality? Journal of Public Economics 2008; 92(3-4); 684-695. 